\title{
SEA LEVEL TREND AND VARIABILITY IN THE SOUTH CHINA SEA
}

\author{
Yanguang $\mathrm{Fu}^{1,2}$, Xinghua Zhou ${ }^{1,2, *}$, Dongxu Zhou ${ }^{2}$, Weikang Sun ${ }^{1}$, Chuanling Jiang ${ }^{1}$ \\ ${ }^{1}$ College of Geodesy and Geomatics, Shandong University of Science and Technology, Qingdao, 266590, China - (ygfu, xhzhou, \\ sunweikang)@fio.org.cn, 1025490456@qq.com \\ ${ }^{2}$ First Institute of Oceanography, Ministry of Natural Resources, Qingdao, 266061, China - zhoudongxu@ fio.org.cn
}

KEY WORDS: Spatiotemporal Analysis, Sea level variability, the South China Sea, Satellite Altimetry, Sea Level Anomaly

\begin{abstract}
:
Sea level rise due to climate change is nonuniform globally, necessitating regional estimates. Spatial-temporal behaviour of sea level anomalies (SLAs) in the South China Sea (SCS) was investigated over 24 years period from 1993 to 2016. Based on the spatial distribution of monthly and seasonal mean SLAs in the SCS, the strong regularity of SLAs performed maybe mainly predominantly driven by monsoonal wind. Variations of SLA were different in each month, which was the largest in July and December, and the smallest in April. Positive sea level linear trends were estimated in most cases. The averaged sea level trend in the SCS showed a rise of $4.42 \pm 0.25 \mathrm{~mm} /$ year from 1993 to 2016 . Further investigations are expected from muliti-resources such as ENSO, wind stress, and vertical land movement data.
\end{abstract}

\section{INTRODUCTION}

Global mean sea level has been rising since the beginning of the $20^{\text {th }}$ century. Sea level rise in the regional ocean is the result of a combination of factors, such as ice sheet melting, pacific decadal oscillation and El Niño-Southern Oscillation.

Satellite altimetry measurements since 1993 have provided high-precision sea level data with global coverage, which has changed our understanding of sea level rise over the past two decades (Church and White, 2006; Hay, et al., 2015).

To identify the sea level trend and variability over the past 300 years, the tide gauge records provide valuable instrumental data from a few seconds to centuries. However, these observations suffer from several limitations: i) although over 2000 tide gauge stations were established during the twentieth century, most of those tide gauges do not cover the entire ocean basins, ii) available most of tide records do not cover the same time period, iii) vertical land movement can affect the tide gauges records, and iv) there is no common reference level for the individual tide gauge records, and this creates a problem of stacking records together (Cipollini et al., 2017).

Satellite altimetry has been the direct observational technique to measure the variation of sea surface height since 1980's. In open ocean areas, sea level measurements with highprecision can be obtained from satellite altimetry. Near the coasts, however, accuracy decreases dramatically. Ocean tide models introduce errors in decimetre level. The altimeter range corrections become incorrect in the official products. With this data, shallow water areas can be investigated with much more data and closer to lines than the official products. Traditionally, satellite altimetry data have been widely used for sea level change studies. However, due to the near coast effects, the accuracy of satellite altimetry data along the coast is significantly lower than that in deep sea. On the other hand, high precision sea level change data can be obtained from gauge stations along coast, which are also linked to a global reference frame.

The South China Sea (SCS) is a marginal sea located in Southeast Asia. Generally, the SCS is a semi-closed basin surrounded by South China, the Philippines, Borneo Island, and the Indo China Peninsula, which connects the East China Sea, the Pacific Ocean, and the Indian Ocean through Taiwan Strait, Luzon Strait, and Malacca Strait, respectively. Due to the unique characteristics of bottom topography and the potential impacts of sea level rise in SCS, understanding sea level changes and monitoring of sea level variability in this area becomes urgent. Thus, many researches have been studied the sea level variation of the SCS in terms of the seasonal (Shaw et al. 1999), and interannual (Rong et al. 2007) sea level variation. And also, some works study the sea level trend in SCS using the along-track satellite data. For example, Li et al. (2003) observed the mean sea level rise rate of $10 \mathrm{~mm} / \mathrm{year}$ in the SCS using TOPEX/Poseidon (T/P) altimetry data from 1993 to 1999. Cheng and Qi (2007) found a mean sea level rose at a rate of $11.3 \mathrm{~mm} /$ year during $1993-2000$ and then fell at a rate of 11.8 $\mathrm{mm} /$ year during 2001-2005. These studies were based on a short-term period of satellite altimeter data that less than 15 years. As those studies revealed, the short record of altimetrybased studies mostly reflects the interannual-decadal variability and cannot obtain the long-term spatial trend patterns. The gridded satellite data is an interpolation of multi-mission satellite-based along-track data, and it has a regular temporal and spatial resolution. Therefore, the multi-mission satellite altimetry gridded data-set were used to spatiotemporal analyses that are not possible with along-track data.

In this work we analysis the spatiotemporal of sea-level variations using the gridded satellite data in the SCS over 24 years period from 1993 to 2016 . The objectives of this paper are: (i) to investigate the spatial distribution of SLAs using satellite data; (ii) to determine the sea level trend in the SCS.

\section{SATELLITE ALTIMETRY DATA}

The delayed-time and reference gridded Sea Level Anomaly (SLA) weekly data product is used due to the better possible spatial and temporal sampling than the real-time maps.

The altimeter data (both along-track and interpolated maps) from all the missions - that is, Jason-3, Sentinel-3A, HY-2A, Saral/AltiKa, Cryosat-2, Jason-2, Jason-1, T/P, ENVISAT, GFO, ERS1/2, are currently produced by SSALTO/DUACS and distributed by AVISO (www.aviso.oceanobs.com). The SLA 
observations used in this paper was 24-year period from January 1993 to December 2016. The detailes can be found in Table 1.

\begin{tabular}{|l|c|c|}
\hline Satellite altimetry & Start date & End date \\
\hline ERS-1 & October 1992 & May 1995 \\
ERS-2 & May 1992 & June 2003 \\
T/P & September 1992 & October 2005 \\
Envisat & April 2002 & March 2012 \\
Jason-1 & January 2002 & June 2013 \\
Jason-2 & June 2008 & Onwards \\
Cryosat-2 & April 2010 & Onwards \\
HY-2A & September 2011 & Onwards \\
SARAL/AltiKa & March 2013 & Onwards \\
Jason-3 & February 2016 & Onwards \\
Sentinel-3A & February 2016 & Onwards \\
\hline
\end{tabular}

Table 1. Satellite date used in the gridded model

The mapping method to produce gridded SLA fields from along-track data is detailed in Le Traon et al. (1998). In the case of delayed-time maps, this data selection implies considering a centered time window of along-track data, taking into account both past and future measurements. Gridded data are produced every week on a $1 / 4^{\circ}$ Mercator projection grid, using the same parameters as given in Dibarboure et al. (2008) with the exception of the long-wavelength error variances that have been adjusted according to the new geophysical corrections (Pascual et al., 2009).

\section{METHODOLOGY}

The sea level trend is defined using basic statistics as the regression coefficient estimated using the least squares method. The sea level trend is given by:

$$
\text { trend }=f \pm U_{p}(f)
$$

where $f$ is the regression coefficient, $U p(f)$ is the expanded uncertainty of regression coefficient. The $f$ and $U p(f)$ are given by the following equation:

$$
\begin{gathered}
f=\frac{\sum_{i=1}^{N}\left[\left(x_{i}-\bar{x}\right)\left(y_{i}-\bar{y}\right)\right]}{\sum_{i=1}^{N}\left(x_{i}-\bar{x}\right)^{2}} \\
U_{p}(f)=\frac{\sqrt{\frac{1}{N-2}\left(y_{i}-\hat{y}_{1}\right)^{2}}}{\sqrt{\sum_{i=1}^{N}\left(x_{i}-\bar{x}\right)^{2}}} t_{p}
\end{gathered}
$$

where $\mathrm{i}=1, \ldots, \mathrm{N}$, where $N$ is the number of sea-level records considered, $y_{i}$ is the actual sea-level measure at the time $x_{i}$ and $\hat{y}_{1}$ the estimated value, and $\bar{x}$ is the average of the $x_{i}$ and $\bar{y}$ the average of the sea-level measurement, $t_{p}$ is the selected confidence level, usually $95 \%$ confidence interval, of $\mathrm{t}$ distribution with $\mathrm{N}-2$ degrees of freedom.

\section{RESULTS AND DISCUSSIONS}

\subsection{Sea level variability}

The long-term average annual altimetry-derived SLA value from 1993 to 2016, were ranged between 0.23 and $1.26 \mathrm{~cm}$. Variation of SLA with respect to longitude and latitude was analysed, the quadratic polynomial fitting is performed respectively, as was shown in Figure 1.

The averaged SLA in the east of SCS is higher than that in west, and low-north high south. As the longitude increases, the SLA declines, but there was an extraordinary rise in four degrees of around $99^{\circ} \mathrm{E}, 100^{\circ} \mathrm{E}, 112^{\circ} \mathrm{E}$ and $118^{\circ} \mathrm{E}$, it can be seen from Figure 2 that the central of strait of Malacca, the north of Gulf of Tonkin, the central of SCS and the west of Taiwan strait were located in the four longitude lines, where the SLAs are significantly larger. As the latitude increases, the SLA declines in the whole level, both in the area of $9^{\circ} \mathrm{N}-15^{\circ} \mathrm{N}$ and $18^{\circ} \mathrm{N}-24^{\circ} \mathrm{N}$, the SLA has changed dramatically. Considering the method of analysing averaged SLA with respect to longitude and latitude and performing quadratic polynomial fitting is only useful and valuable for a single water body (i.e., the SCS), other areas such as Malacca Strait, Sulu Sea and Celebes Sea should be excluded in this analysis to avoid bias especially by SLA in Malacca Strait which behaves differently from the rest of the SCS.

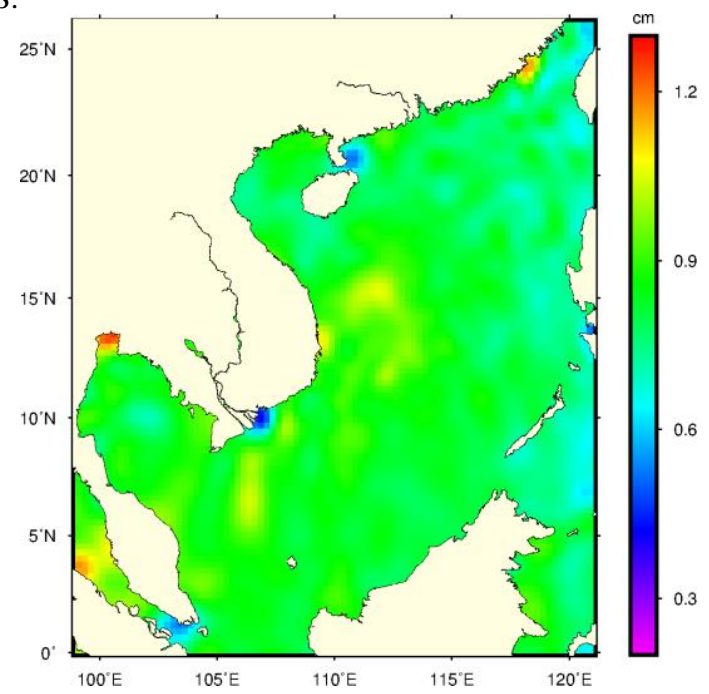

Figure 1. Spatial distribution of annual mean SLA between 1993 and 2016
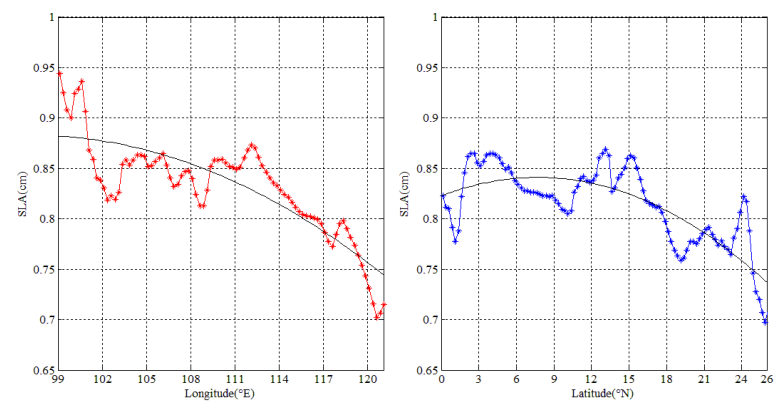

Figure 2. Variations of annual mean SLA between 1993 and 2016 with respective to longitude and latitude

Before analyzing the sea level variability in the SCS, the correlation of SLA time series between satellite altimetry data and tide station observations was firstly compared, as shown in Figure 3.

Through the correlation analysis of the two data sets, $71.43 \%$ of the stations' correlation coefficient was above 0.80 , $48.57 \%$ was up to 0.90 above.

In the north of SCS, between $15^{\circ} \mathrm{N}$ and $26^{\circ} \mathrm{N}$, the two SLA time series in five of seven stations were positively corrected with a higher correlation coefficient than 0.60 . Only one station showed a low positive correlation (0.43) between satellite 
altimetry and tide gauge data. Minimum negative correlation with -0.48 was found in the Gulf of Tonkin.

High correlations were found in the Strait of Malacca and Singapore, where there were 11 stations showed a high correlation ranging from 0.88 to 0.95 between altimetry and tide gauges, except one station is low with 0.67

In the Gulf of Thailand, the sea-level anomalies of three stations were well correlated between satellite and tide gauge with the correlation in the range $0.55-0.81$.

In the Southeast of SCS, the correlation coefficients in seven of nine stations were above 0.88 , among which the KOTA KINABALU station showed the highest correlation between the tide gauge and satellite data (0.98). The other two stations, the sea-level anomalies were positively correlated with the lowest correlation coefficient of 0.08 and 0.20 .

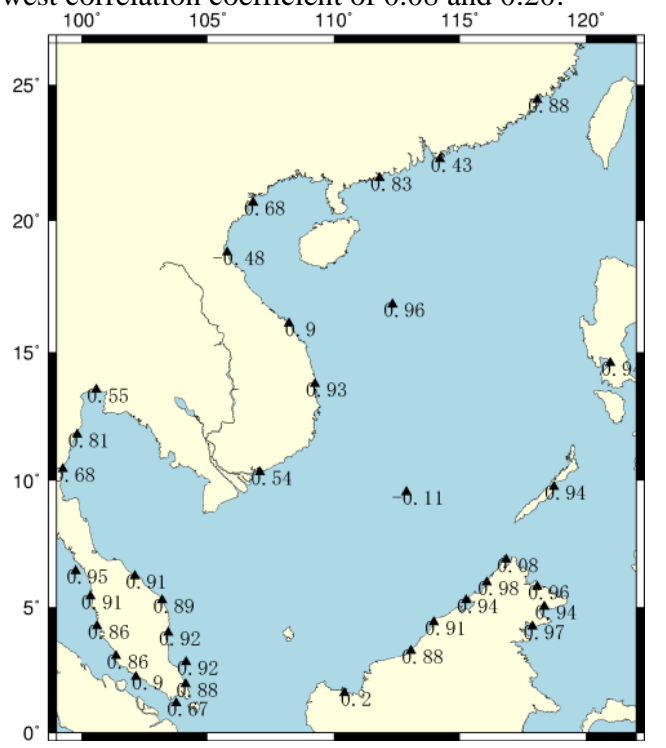

Figure 3. Correlation of observations between satellite altimetry and tide gauge data in tide stations

Distributions of the monthly averaged SLAs during 1993 2016 are plotted in Figure 4. The SLA distribution in each month has strong regularity. In the Gulf of Thailand, the SLA reached its maximum of $29.4 \mathrm{~cm}$ in December, following which it declined to a minimum of $-21.03 \mathrm{~cm}$ in July. However, the situation in the central SCS is the opposite. The SLA is at the lowest level of $-12.69 \mathrm{~cm}$ in January and at a peak of $18.35 \mathrm{~cm}$ in July, showing an obvious evolution from the center to surrounding areas. Because of differing climatic conditions, it can be seen that the SLA variations are different in each month. The SLA exhibits the largest change in July and December, with magnitude ranging from -10.48 to $29.40 \mathrm{~cm}$ and from -21.03 to $18.35 \mathrm{~cm}$, respectively. The month with the smallest change is April, with magnitude ranging from -8.63 to $10.24 \mathrm{~cm}$.
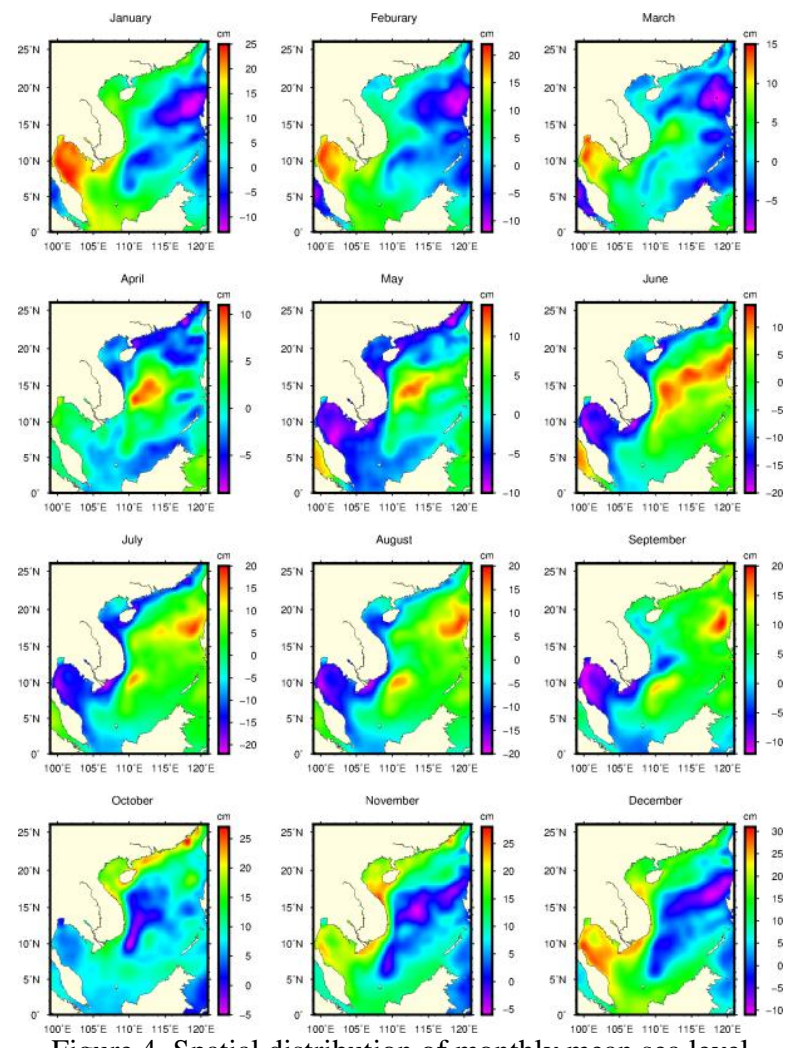

Figure 4. Spatial distribution of monthly mean sea level anomalies during 1993-2016.

The seasonally variations maps of sea-level signals were calculated by averaging season by season: January-FebruaryMarch / April-May-June / July-August-September / OctoberNovember-December from 1993, as is shown in Figure 5.

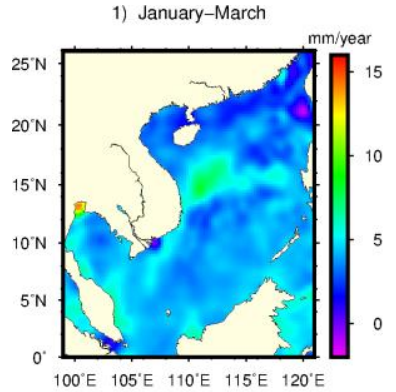

2) Apirl-June
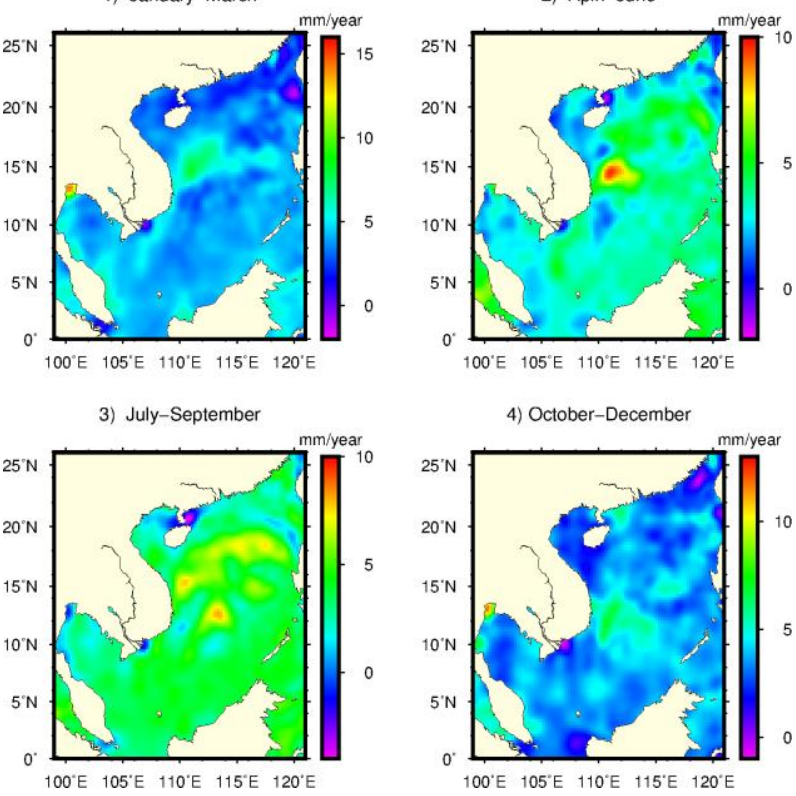

4) October-December

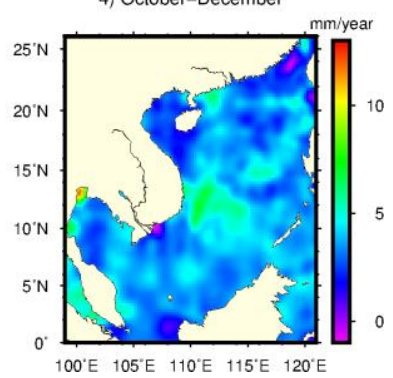

Figure 5. Satellite altimetry sea-level trend in four seasons.

Seasonal sea level variability across the SCS is predominantly driven by the Asian monsoonal wind (Wyrtki, 1961; Lau et al., 1998; Ding and Johnny, 2005; Tan et al., 2006; Liang and Evans, 2011). During January-March, the sea level in the SCS falls and the area with negative SLA values increases because water flows toward the southwest under the influence of the northeast monsoon. During April-June, weakening of the northeast monsoon means water flows from 
the southwest toward the northeast. Between July and September, the SLA is gradually become lower in the northeast because of the role of the Kuroshio Current and the effect of the summer southwest monsoon. During October-December, with gradual weakening of the southwest monsoon, the sea surface of the SCS reflects the transition from the summer monsoon into the winter monsoon, which reduces the impact on sea level change during this period.

In the northern part of the SCS, the spatial distribution of SLAs has opposite features during winter and summer, which is in accord with monsoon intensity. This suggests the SLAs in this area are closely related to the changes of the monsoon, i.e., positive seasonal SLAs are induced during boreal winter by wind shear during the northeast monsoon, whilst negative SLAs during boreal summer are caused by the southwest monsoon.

\subsection{Sea level trend analysis}

The spatial variability of sea level trend was shown in Figure 6. In the SCS, the sea-level trend was ranging from -0.74 to $9.00 \mathrm{~mm} / \mathrm{year}$, the entire SCS area showed a positive sea level trend except several locations in the southern Laos and the Qiongzhou Strait.

The changes of the regional SLA are affected by global ocean climate events (such as ENSO). Furthermore, they are closely related to the abnormal changes of local climate, such as marine events (ENSO), air pressure, wind, air temperature and sea surface temperature (SST).

During 2005 2010, three strong La Niña events led to abnormally high sea level in the SCS. In addition, affected by the low-frequency variation of the Southern Oscillation and the North Pacific decadal oscillation, the wind stress displayed strong easterly wind anomaly in the central-west basin of the SCS, resulting in anomaly negative wind stress curl, which also led to abnormally high sea level in the SCS (Wang et al. 2017).

The SLA, according to the relevant studies, i.e., Wang et al., (2017), Qiu et al., (2015), has no significant correlation with SST, air temperature and air pressure, but is closely related to ENSO events. The negative anomalies always occur during the El Niño events, while the positive anomalies occur during the La Niña (late El Niño) events.

The averaged trend of sea level anomalies in the SCS, shows a rise of $4.42 \pm 0.25 \mathrm{~mm} /$ year from 1993 to 2016 . This observed positive trend is also in agreement with the results of Handoko et al. (2017), which estimate the mean rate of sea level rise of $4.20 \pm 0.20 \mathrm{~mm} /$ year around the Indonesian seas over 1993 to 2015 .

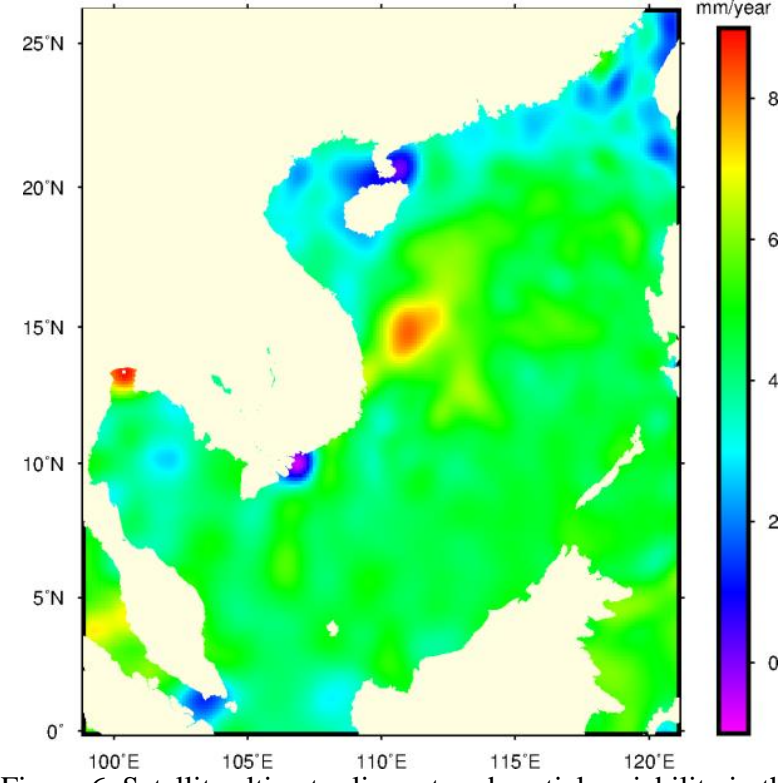

Figure 6. Satellite altimetry linear trend spatial variability in the SCS (1993-2016).

\section{SUMMARY AND CONCLUSIONS}

Global climate changes have been the focus research area. One of the key indicators of global climate changes is the sea level rising. Globally, the sea level rising is caused by the global temperature increase, which includes the thermal expansion of sea water and the melt of ices in glaciers and polar regions. However, regional sea level changes will be affected by not only the global effects but also regional effects such as regional temperature, currents, wind, precipitation, air pressure and etc. The aim of this work was to analysis the spatiotemporal of SLA of the SCS retrieved from gridded altimetry data over 24 years from 1993 to 2016 .

Spatial distribution of SLA was investigated by calculated the annual and monthly mean sea-level signal from satellite altimetry data. Variation of annual mean SLA with respect to longitude and latitude was analysed, the SLAs in four regions, such as the central of strait of Malacca, the north of Gulf of Tonkin, the central of SCS and the west of Taiwan strait, were significantly larger. The SLA distribution of each month has a strong regularity, which is mainly predominantly driven by monsoonal wind. We observed that the variations of SLA were different in each month, SLA had the largest change in July and December, and the smallest change month is April, magnitude vary between -8.63 and $10.24 \mathrm{~cm}$.

With regard to the sea-level trend, almost in all cases analysed positive rates were observed. The averaged linear sealevel trend in the SCS, shows a rise of $4.42 \pm 0.25 \mathrm{~mm} /$ year from 1993 to 2016. The reasons of abnormal rising of sea level in the central and western parts of the SCS would be deeply investigated by combined with ENSO, wind data and vertical land motivation data.

\section{ACKNOWLEDGEMENTS}

The authors would like to acknowledge the AVISO for providing the gridded satellite altimetry data. This work was supported by the National Key R\&D Program of China (2016YFB0501700, 2016YFB0501703 and 2017YFC0306003), the National Natural Science Foundation of China (41876111, 
40706038, 41706115 and 41806214) and the Natural Science Foundation of Shandong Province (ZR2017QD011).

\section{REFERENCES}

Cheng, X., Qi, Y., 2007. Trends of sea level variations in the South China Sea from merged altimetry data. Global Planet Change, 57:371-382. doi.org/10.1016/j.gloplacha.2007.01.005

Church, J.A., White, N.J., 2006. A twentieth century acceleration in global Sea-level rise. Geophys. Res. Lett., 33: L01602. doi:10.1029/2005GL024826.

Cipollini, P., Calafat F.M., Jevrejeva, S., Melet, A., Prandi, P., 2017. Monitoring sea level in the coastal zone with satellite altimetry and tide gauges. Surv. Geophys., 38: 33-57.

Dibarboure, G., Lauret O., Mertz, F., Rosmorduc, V., 2008. SSALTO/DUACS user handbook: (M) SLA and (M) ADT near-real time and delayed time products. SALP-MU-P-EA21065-CLS, 1.9 ed., 39 pages.

Ding, Y., Johnny, C.L.C., 2005. The East Asian summer monsoon: an overview. Meteorol. Atmos. Phys., 89, 117-142, doi:10.1007/s00703-005-0125-z.

Handoko, E., Fernandes, M., Lázaro, C., 2017. Assessment of altimetric range and geophysical corrections and mean sea surface models - impacts on sea level variability around the Indonesian Seas. Remote Sens-basel 9, 102. doi.org/10.3390/rs9020102.

Hay, C.C., Morrow, E., Kopp, R.E., Mitrovica, J.X., 2015. Probabilistic reanalysis of twentieth-century sea-level rise. Nature, 517 (7535): 481-484.

Lau, K.-M., Wu, H.-T., and Yang, S., 1998. Hydrologic processes associated with the first transition of the Asian Summer Monsoon: a pilot satellite study, B. Am. Meteorol. Soc., 79, 1871-1882, doi:10.1175/1520-

0477(1998)079<0061:APGTWA>2.0.CO;2.

Le Traon, P.Y., Ogor, F., 1998. ERS-1/2 orbit improvement using TOPEX/POSEIDON: The $2 \mathrm{~cm}$ challenge. J. Geophys. Res., 103, 8045-8057.

Liang, A. and Evans, J.L., 2011. Introduction to Tropical Metorology, $2^{\text {nd }}$ Edn., COMET Program, University

Corporation for Atmospheric Research.

Pascual, A., Boone, C., Larnicol, G., Le Traon, P.Y., 2009. On the quality of Real-Time altimeter gridded fields: Comparison within situ data. J. Atmos. Ocean. Tech., 26: 556-569. doi.org/10.1175/2008JTECHO556.1.

Qiu, F., Fang, W., Zhu, D., Cha, J., 2015. Characteristics and mechanism of the sea level rise in the South China Sea during 2005 2010 (In Chinese). J. Trop. Oceanogr., 34 (5): 11-18. doi.org/10.11978/2014123.

Rong, Z., Liu, Y., Zong, H., Cheng, Y., 2007. Interannual sea level variability in the South China Sea and its response to ENSO. Global Planet Change, 55: 257-272. doi.org/10.1016/j.gloplacha.2006.08.001.
Shaw, P.T., Chao, S.Y., Fu, L.L., 1999. Sea surface height variations in the South China Sea from satellite altimetry. Oceanol. Acta., 22. doi.org/ 10.1016/S0399-1784(99)80028-0.

Tan, C.K., Ishizaka, J., Matsumura, S., Yusoff, F. M., Mohamed, M.I.H., 2006. Seasonal variability of SeaWiFS chlorophyll $\mathrm{a}$ in the Malacca Straits in relation to Asian monsoon. Cont. Shelf Res., 26, 168-178, doi:10.1016/j.csr.2005.09.008.

Wang, H., Liu, K., Gao, Z., Fan, W., LIU, S., LI, J., 2017. Characteristics and possible causes of the seasonal sea level anomaly along the South China Sea coast. Atca Oceanol. Sin., 36 (1): 9-16. doi.org/10.1007/s13131-017-0988-0.

Wyrtki, K.,1961. Physical Oceanography of the Southeast Asian Waters, Scientific Results of Maritime Investigations of the South China Sea and Gulf of Thailand 1959-1961, NAGA Report 2, Scripps Institute of Oceanography, $195 \mathrm{pp}$. 